Journal of Machine Engineering, 2020, Vol. 20, No. 3, 117-124

ISSN 1895-7595 (Print) ISSN 2391-8071 (Online)

Received: 12 November 2019 / Accepted: 20 February 2020 / Published online: 25 September 2020

additive manufacturing, PEEK, prosthetic implants,

Marcin KROLIKOWSKI ${ }^{1 *}$

Damian PRZESTACKI ${ }^{2}$

Tadeusz CHWALCZUK ${ }^{2}$

Ewa SOBOLEWSKA ${ }^{3}$

Malgorzata TOMASIK ${ }^{4}$

\title{
ADDITIVE MANUFACTURING OF POL YETHER ETHER KETONE - PEEK PARTS WITH SURFACE ROUGHNESS MODIFICATION BY A LASER BEAM
}

\begin{abstract}
The physicochemical properties of polyether ether ketone (PEEK) allow to use this material for prosthetic restorations applied in implant prosthetics. So far, such attempts have been made in the technology of milling rough material solids of this polymer, but the surface quality was unsatisfactory. Therefore, the production of these materials by additive manufacturing techniques was proposed and an attempt was made to shape their surface using a laser. The possibilities of the method are determined in the paper and preliminary works related to the product surface shaping are presented. The process of making individual prosthetic restorations from the PEEK material by the additive method together with the technology of laser modification of the geometric structure of the material surface for applications in implant prosthetic treatment of patients is innovative and has not been used so far.
\end{abstract}

\section{INTRODUCTION}

In bone implantology, and especially in dental implantology, metals and their alloys are most often used. Unfortunately, metals (such as nickel, chromium, cobalt, palladium) are important etiological factors of contact allergy because they are characterized by high chemical reactivity and high biological activity [1]. Estimates show that from the general population about $3 \%$ of men and $17 \%$ of women are allergic to nickel [1-2]. Even allergies to titanium implants (titanium is considered a completely neutral metal to the body) in light of the clinical research seem to be a growing, though rare, problem. There is evidence that titanium implants can cause a side reaction of the body due to the admixture of the metals used in their production [3].

\footnotetext{
1 West Pomeranian University of Technology, Szczecin, Faculty of Mechanical Engineering and Mechatronics, Department of Manufacturing Engineering, Szczecin, Poland

2 Poznan University of Technology, Faculty of Mechanical Engineering and Management, Institute of Mechanical Technology, Poznan, Poland

${ }^{3}$ Pomeranian Medical University in Szczecin, Faculty of Medicine and Dentistry, Department of Dental Prosthetics, Szczecin, Poland

${ }^{4}$ Department of Interdisciplinary Dentistry, Pomeranian Medical University, Szczecin, Poland

${ }^{*}$ E-mail: marcin.krolikowski@zut.edu.pl https://doi.org/10.36897/jme/119670
} 
An alternative material to titanium is zirconium, but the mechanical properties of this material, especially its high hardness, cause unfavourable stress in the bone around the implant. The use of zirconia prosthetic restorations is also not recommended for all patients due to adverse effects on other materials in the patient's mouth and own teeth in the opposing arch.

It has been three decades of hard and rigid implant prosthetics based on metal alloys, zirconia and ceramics. Today, patients have permanent prostheses mounted on implants and suffer from very painful complications due to temporomandibular joint dysfunction - CMD - craniomandibular disorders. The patient undergoing implant prosthetic treatment with a significantly lower perception of sensation within the chewing apparatus generates many times higher occlusal forces during the process of crushing food bites. In combination with a very rigid metal-ceramic and/or alternatively zirconium-ceramic crown, implant prosthesis, hard titanium connector and bone-fused implant, is a direct and permanent cause of the progressive temporomandibular joint dysfunction and subsequent further health complications.

An alternative material for this type of implant may be polyether ether ketone (PEEK). The results of published scientific studies have shown that PEEK is a material with excellent biocompatible properties that are used in medicine and dentistry [4-6]. Currently, polyether ether ketone (PEEK) is increasingly used in orthopaedics (spine and hip prostheses) and maxillofacial surgery. It belongs to the new generation of highly cross-linked, non-absorbent plastics, which are similar in physical parameters (e.g. flexibility) to natural substances (e.g. bones) present in the human body. It can also be used in dental implantology due to its very favourable biological properties: very high biocompatibility, very high biostability (structurally aromatic semi-crystalline nature), high, constant corrosion and hydrological resistance including very low water absorption $(0.65 \mu \mathrm{g} / \mathrm{mm} 3)$, chemical inertness to body fluids, very low solubility and sterilization [7-8]. Thus, the PEEK material seems to be a very promising material for prosthetic restorations. It is not yet widely used in dental prosthetics so far.

The results of experimental and finite element method studies on implant prototypes [9] have shown that PEEK, in contrast to titanium, allows the improvement of occlusal forces distribution around the implant. For this reason, it may prove to be a much safer material for the prosthetic treatment of patients in the long-term observation period than currently used materials such as metal alloys and zirconia. Based on the literature review [1-9], it should be indicated that PEEK may be a recommended material for patients allergic to titanium. It is also a material visible in X-rays, which allows you to control the tightness of the prosthetic reconstruction. An extremely important feature of this material is the lack of ferromagnetic properties, which allows for full diagnostic imaging, including magnetic resonance imaging in patients using PEEK prosthetic restorations without the risk of heating-up of these components and especially without the risk of artefacts in the field of head and neck imaging. The bioactive properties of a PEEK material and its mechanical properties depend significantly on the method of manufacturing and surface treatment of the material.

Initially, PEEK was a material used in the selective laser sintering technology. Semifinished products of this material are also made by extrusion molding methods - extrusion and calendering [10-15]. Only recently has it become a material also manufactured using additive techniques (the FDM method - Fused Deposition Modelling, identical to the FFF 
method - Fused Filament Fabrication), owing to the development of a technology that allowed it to be printed at a very high (for plastic) temperature [13], oscillating around $400^{\circ} \mathrm{C}$. Also, the PEEK surface shaping methods described so far have involved an change in the surface structure by e.g. sandblasting, polishing, coating the surface with carbon monoxide or adding sulphonamides to the material. Publications [4-6, 16-18] indicate the need for further research on the surface structure of materials dedicated to making prosthetic restorations and implants due to the required smoothness of the surface at the place of contact of the soft tissue with the implant and emerging bacterial habitats.

Therefore, the authors of the paper attempted to shape the surface of samples of a PEEK material produced by the additive technique with a technological $\mathrm{CO}_{2}$ laser. This paper focuses on the description of the manufacturing process using the additive technique and the selection of parameters for laser surface smoothing.

\section{MATERIALS AND METHODS}

The starting material, polyether ether ketone (PEEK) in the form of a $1.75 \mathrm{~mm}$ filament was purchased from the "Carbon Fox" company, which imported it from a recognised US manufacturer. Samples of polyether ether ketone were prepared by the additive technique on a CreatBot F160 device capable of extrusion at speeds up to $100 \mathrm{~mm} / \mathrm{min}$ at a maximum head temperature of $420^{\circ} \mathrm{C}$, table temperature up to $150^{\circ} \mathrm{C}$ and chamber temperature up to $70^{\circ} \mathrm{C}$. The extrusion rate and flow temperature were selected experimentally.

The obtained results allowed to get best achievable in this setup parameters of additive manufacturing under given technological conditions. The head temperature was $400^{\circ} \mathrm{C}$ at an extrusion rate of $30 \mathrm{~mm} / \mathrm{s}$. The layer thickness was set to $0.2 \mathrm{~mm}$ with a $10 \%$ infill density to avoid shrinkage and deformation of the outer surface. The internal chamber of the additive manufacturing device was actively heated to $70^{\circ} \mathrm{C}$. The wall thickness was $1.6 \mathrm{~mm}$, as was the thickness of the base and upper surface of the samples. The samples were then subjected to recrystallization heating at $200^{\circ} \mathrm{C}$ for 2 hours.

The research in the scope of the possibility of smoothing the surface of the obtained samples was carried out by concentrating energy in the surface layer - selection of surface shaping parameters using laser technique, remelting the surface with a laser beam [19-21]. The tests were carried out on samples produced on the CreatBot F160 device (Fig. 1a). Flat and round samples (Fig. 1b) have been subjected to a laser beam with variable energy concentration and spot diameter in order to obtain the proper material flow in the surface layer and to remove marks after additive manufacturing on the side and front surfaces.

The exposure parameters of curvilinear and surface elements have been experimentally selected for different surfaces of models by iterative methods. Laser modification of the geometric structure of the surface took place on an experimental stand consisting of a technological $\mathrm{CO}_{2}$ laser Trumpf TLF 2600 with nominal power of $2.6 \mathrm{~kW}$ and a lathe TUM35D1 necessary for shifting and processing the object (Fig. 2) Samples with dimensions of $\varnothing 20 \times 40 \mathrm{~mm}$ were shown during additive manufacturing (a) and showing the internal structure of the filling (b) in Fig. 1. 
a)

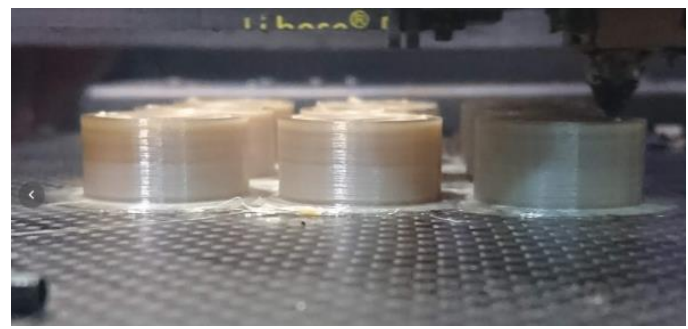

b)

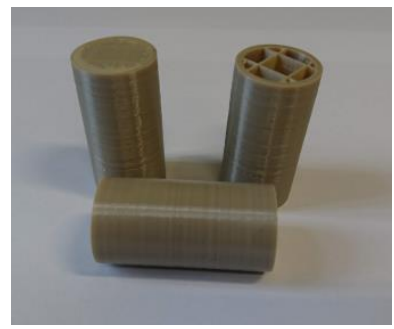

Fig. 1. The view, shape and dimensions of PEEK samples manufactured using the FFF technique. Macroscopic examinations: a) samples at printing bed during manufacturing, b) printed samples

a)

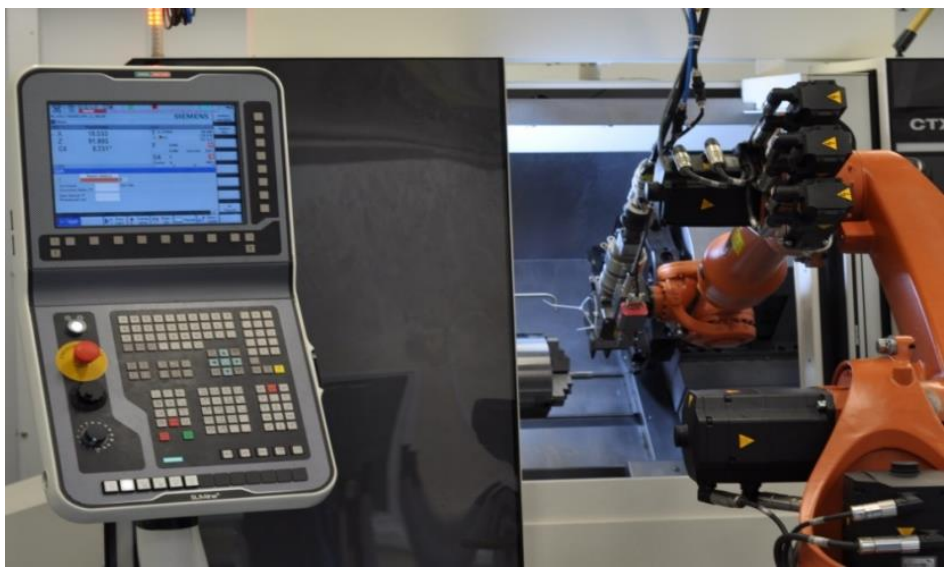

b)

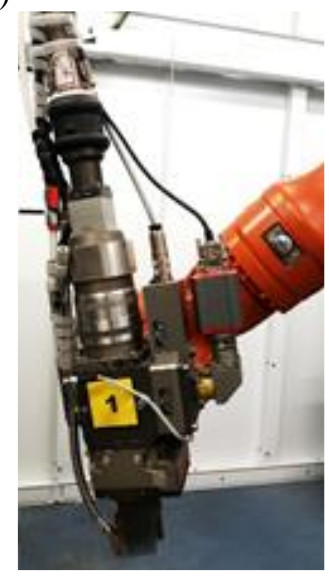

Fig. 2. The test stand for laser assisted turning: a) Trumpf TruDiode 3006 with a CNC lathe, b) laser head

Samples in the form of $30 \times 40 \times 3 \mathrm{~mm}$ cuboids were also made for the surface shaping research.

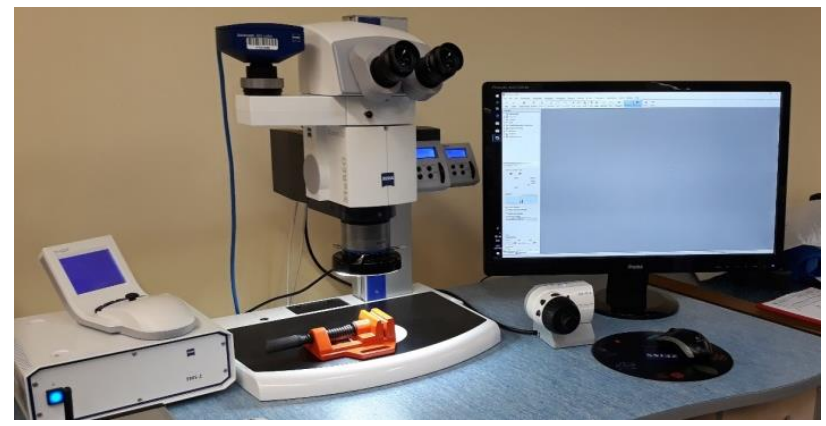

Fig. 3. The laboratory stand for microscopic measurements. A ZEISS SteREO Discovery V20 microscope and a computer with dedicated software

\section{RESULTS AND DISCUSSION}

The polyether ether ketone (PEEK) was produced by the additive technique by applying the molten plastic filament layer by layer, thus bonding them with previous detail layers until full dimensions of designed samples were obtained. The formation process took place at a high temperature of $400^{\circ} \mathrm{C}$. 
Despite the measures minimizing the PEEK linear shrinkage, it was not possible to obtain the sample surface free from defects in all cases (Fig. 4). The linear shrinkage combined with uneven cooling is responsible for the formation of stress, cracks and porosity in the material. Therefore, these defects usually result from deformation and are associated with a change in the dimensions of the material during solidification and cooling of the material.

The material extrusion process itself is also carried out under strictly defined conditions and due to the partial thermal degradation of the material, when switching between the layers of the model, structure errors arise. In the case of thermoplastic materials being mixtures, e.g. ABS (acrylonitrile-butadiene-styrene terpolymer), this process is not as rapid as in the case of crystalline materials like PEEK. Despite providing thermal conditions that reduce shrinkage and facilitate adhesion - the working platform of the device heated to $150^{\circ} \mathrm{C}$ and the chamber heated actively to $70^{\circ} \mathrm{C}$, it was not possible to avoid deformation in the case of flat samples (Fig. 4). Also in the case of round samples, the printing plane shifts are noticeable due to obvious positioning errors multiplied by the inertia of the thermal regulation of the chamber, table and head. The obtained samples, due to recrystallization heating, however, have a homogeneous structure, which is indicated by the correct colour and no unfavourable discolouration, occurring in the PEEK material right after the additive manufacturing process due to thermal gradients and interlayer cooling.

a)

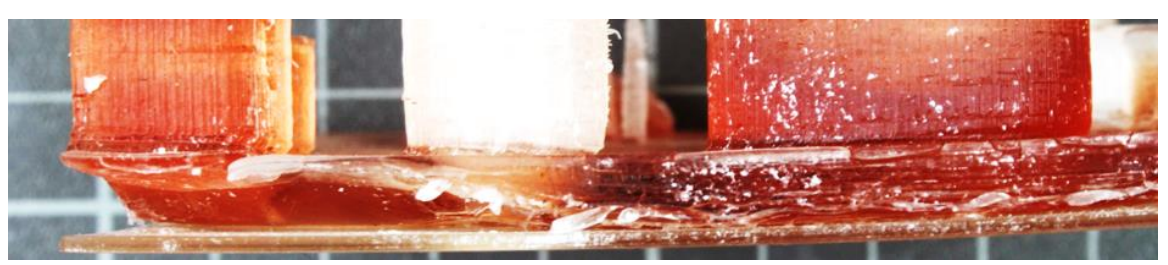

b)

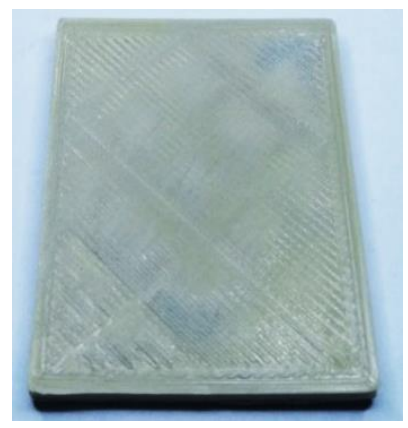

c)

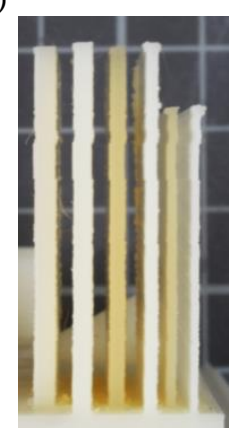

Fig. 4. The surface view of samples with defects - the PEEK material, additive technique, a) an example of delamination of manufactured materials, b) and c) an example of the FDM print plane shift. Macroscopic examinations

Surface shaping with a diode laser was a very complex process. Experimental parameters were selected based on the relative laser power and the associated relatively low melting point of PEEK. At the initial stage of testing, the samples underwent charring and burning due to too much laser power - Fig. 5. At the next change in process parameters, the material underwent "swelling" during surface shaping-remelting - Fig. 6. Subsequent tests 
contributed to obtaining the melted surface of the material (Fig. 7) of satisfactory quality. Such samples meet the authors' expectations in terms of qualitative assessment carried out organoleptically and using macroscopic examinations. They will be subject to further qualitative analysis in terms of applications for dental implants, which is particularly related to the assessment of their surface roughness.

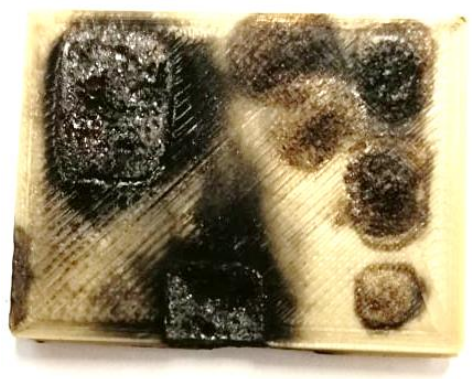

Fig. 5. The surface view of samples after shaping the surface with a technological $\mathrm{CO}_{2}$ laser - the PEEK material produced by the additive technique. Local burns. Macroscopic examinations
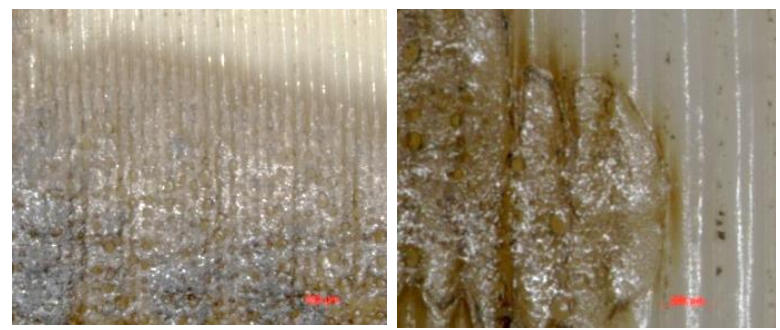

Fig. 6. The surface view of the sample after shaping the surface with a diode laser, the PEEK material produced by the additive technique. Clearly visible "swelling" of the material. Process parameters: P-100 W laser power, heating speed $v_{\mathrm{c}}=55.57 \mathrm{~m} / \mathrm{min}$, number of passes (heating repetitions) 20, shielding gas $\mathrm{CO}_{2}$ pressure 4 bar, diameter of the laser beam $d_{1}=1.2 \mathrm{~mm}$. Optical microscopy

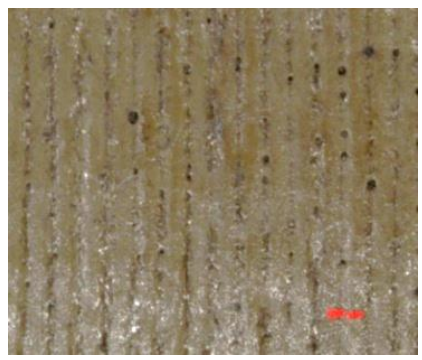

Fig. 7. The surface view of the samples after shaping the surface with a technological $\mathrm{CO}_{2}$ laser - the PEEK material produced by the additive technique. Process parameters: P-100 W laser power, heating speed $v_{\mathrm{c}}=70.18 \mathrm{~m} / \mathrm{min}$, feed speed $v_{1}=0.074 \mathrm{~m} / \mathrm{s}$, number of passes (heating repetitions) 10 , shielding gas $\mathrm{CO}_{2}$ pressure 4 bar, diameter of the laser beam $d_{1}=1.2 \mathrm{~mm}$. Optical microscopy

\section{CONCLUSION}

This work is an attempt to produce polyether ether ketone (PEEK) by the additive technique and to shape the material thus produced by the influence of a technological $\mathrm{CO}_{2}$ 
laser on its surfaces to improve the surface topography. The authors limited themselves to determining the manufacturing process parameters and shaping the surface dedicated to dental implants. It was found that the proper process parameters were: laser power P-100 W, heating speed $v_{\mathrm{c}}=70.18 \mathrm{~m} / \mathrm{min}$, feed speed $v_{1}=0.074 \mathrm{~m} / \mathrm{s}$, number of passes (heating repetitions) 10 , shielding gas $\mathrm{CO}_{2}$ pressure 4 bar, laser beam diameter $d_{1}=1.2 \mathrm{~mm}$.

In further papers related to this issue, topographic and bacteriological tests and phase analysis of shaped plastics will be carried out, as well as the use of secondary polymerization, which will be aimed at obtaining a greater smoothness of the material dedicated for prosthetic implants.

The use of polyether ether ketone is a new opportunity to replace metal or ceramic implants in medicine. The satisfactory strength of the material in the absence of a tendency to create corrosive and (with a smooth surface) bacterial focuses causes that materials from the group of polyether ether ketone - PEEK can be successfully used as functional elements in the human body.

\section{REFERENCES}

[1] KRECISZ B., CHOMICZEWSKA D., PALCZYNSKI C., KIEC-SWIERCZYNSKA M., 2012, Contact Allergy to Metals in Adolescents. Nickel Release from Metal Accessories 7 Years After the Implementation of the EU Nickel Directive in Poland, Allergy, 67/5, 270-276.

[2] DABROWSKA D., ROSZKIEWICZ J., SOSNOWSKI G., WOJCIK T., 2007, Allergy to Metal Implants Used in Orthopaedics, Post. Dermatol. Allergol., 24, 99-103.

[3] SPIEWAK R., MOED H., 2007, Allergic Contact Dermatitis to Nickel: Modified in Vitro Test Protocols for Better Detection of Allergen-Specific Response, Contact Dermatitis, 56, 63-69.

[4] SCHWITALLA A., MÜLLER W.D., 2013, PEEK Dental Implants: A Review of the Literature, J. Oral. Implantol., $13 / 6,743-749$.

[5] MISHRA S., CHOWDHARY R., 2019, PEEK Materials as an Alternative to Titanium in Dental Implants: A Systematic Review, Clin. Implant. Dent. Relat. Res., 21/1, 208-222.

[6] NAJEEB S., BDS Z.K., BDS S.Z., BDS M.S,. 2013, Bioactivity and Osseointegration of PEEK Are Inferior to Those of Titanium: A Systematic Review, J. Oral. Implantol., 42/6, 512-516.

[7] KURTZ S.M., DEVINE J.N., 2007, PEEK Biomaterials in Trauma, Orthopedic, and Spinal Implants, Biomaterials, 28/32, 4845-4869.

[8] TOTH J.M, WANG M., ESTES B.T., SCIFERT J.L., SEIM H.B., TURNER A.S., 2006, Polyetheretherketone as a Biomaterial for Spinal Applications, Biomaterials, 27/3, 324-334.

[9] MENINGAUD J.P., SPAHN F., DONSIMONI J.M., 2012, After Titanium, Peek? Rev. Stomatol. Chir. Maxillofac., $113 / 5,407-410$.

[10] SIEMINSKI P., BUDZIK G., 2015, Additive Techniques. 3D Print, 3D Printers, OWPW, Warsaw.

[11] GALETA T., RAOS P., SOMOLANJI M., 2012, Impact of Structure and Building Orientation on Strength of 3D Printed Models, KGK Kautschuk, Gummi, Kunststoffe, Croatia.

[12] PLATEK P., ZAHOR M., 2009, Application of the FDM Method of Rapid Prototyping in the Design Process of the $5.56 \mathrm{Mm}$ Modular Small Arms System (MSBS-5.56), Problems of Armament Techniques, WITU, 110/2, 95-102, (in Polish).

[13] Information materials of the Stratasys company, a manufacturer of prototyping machines in the FDM technique: staratasys.com, fortus.com, dimensionprinting.com.

[14] PEYRE P., 2015, Experimental and Numerical Analysis of the Selective Laser Sintering (SLS) of PA12 and PEKK Semi-Crystalline Polymers, Journal of Materials Processing Technology, 225, 326-336.

[15] GUAN G., 2015, Evaluation of Selective Laser Sintering Processes by Optical Coherence Tomography, Materials and Design, 88, 837-846.

[16] WANG C., WANG S., YANG Y., JIANG Z., DENG Y., SONG S., YANG W., CHEN Z.G., 2018, Bioinspired, Biocompatible and Peptide-Decorated Silk Fibroin Coatings for Enhanced Osteogenesis of Bioinert Implant, J. Biomater. Sci., Polym. Ed., 29/13, 1595-1611. 
[17] HAN X., YANG D., YANG C., SPINTZYK S., SCHEIDELER L., LI P., LI D., GEIS-GERSTORFER J., RUPP F., 2019, Carbon Fiber Reinforced PEEK Composites Based on 3D-Printing Technology for Orthopedic and Dental Applications, J. Clin. Med., 8/2, 240, https://doi.org/10.3390/jcm8020240.

[18] BUBIK S., PAYER M., ARNETZL G., KALTENEGGER H., LEITHNER A., KLAMPFL A., LOHBERGER B., 2017, Attachment and Growth of Human Osteoblasts on Different Biomaterial Surfaces, Int. J. Comput. Dent., 20/3, 229-243, Quintessence Pub. Co.

[19] PRZESTACKI D., BARTKOWSKA A., KUKLINSKI M., KIERUJ P., 2018, The Effects of Laser Surface Modification on the Microstructure of 1.4550 Stainless Steel, MATEC Web Conf., 237, D2ME, doi.org/10.1051/ matecconf/201823702009.

[20] KUKLINSKI M., BARTKOWSKA A., PRZESTACKI D., 2018, Investigation of Laser Heat Treated Monel 400, MATEC Web Conf., 219, BalCon, doi.org/10.1051/matecconf/201821902005.

[21] CHWALCZUK T., PRZESTACKI D., SZABLEWSKI P., FELUSIAK A., 2018, Microstructure Characterization of Inconel 718 After Laser Assisted Turning, MATEC Web Conf., 188, 02004, https://doi.org/10.1051/matecconf/ 201818802004. 